http://jmscr.igmpublication.org/home/ ISSN (e)-2347-176x ISSN (p) 2455-0450 crossref DOI: https://dx.doi.org/10.18535/jmscr/v10i1.31

\title{
A Prospective Study of Acceptability, Safety and Efficacy of Postpartum Insertion of Intrauterine Copper Device (CU-T380a) in Tertiary Care Teaching Hospital in South India
}

\section{Shanthi Ponusamy ${ }^{1}$, Minthami Sharon*², Akanksha Singh ${ }^{3}$}

${ }^{1}$ Associate Professor, Department of Obstetrics and Gynaecology, Shree Balaji medical college and hospital, Chennai, Tamil Nadu, India

${ }^{2}$ Associate Professor, Department of Obstetrics and Gynaecology, Shree Balaji medical college and hospital, Chennai, Tamil Nadu, India

${ }^{3}$ Resident Department of Obstetrics and Gynaecology, Shree Balaji medical college and hospital, Chennai, Tamil Nadu, India

*Corresponding Author

Minthami Sharon

\begin{abstract}
Introduction: Many national postpartum family planning (PPFP) programmes are progressively including postpartum intrauterine contraceptive devices (PPIUCD). Effectiveness of Intrauterine contraceptive device (IUCD) is an inexpensive method of family planning which is reversible, once inserted gives 5-10 years of protection against pregnancy.

Aim: We aimed to compare numerous IUCD-related clinical parameters to assess acceptability, safety, and efficacy in immediate postpartum vaginal insertion, intra-caesarean insertion.

Materials and Methods: It was a prospective analysis of data collected regarding maternal age, socioeconomic status, education, occupation, and parity of 354 eligible postpartum mothers in a tertiary care teaching hospital and Medical College in Tamil Nadu from January 2017 to January 2020. These women's data included acceptability, safety, and efficacy, as well as the spontaneous expulsion rate of IUCD, reasons for removal, and IUCD up to a 12-month follow-up period.

Results: The majority of the women were between the ages of 24 and 35, literate, primiparous, employed, and from a middle/lower socioeconomic status. Leukorrhea and abdominal discomfort were the most common side effects at 6 weeks, 6 months, and a year, followed by vaginal bleeding. The majority of $C u$ - $T$ was withdrawn in this trial due to $\mathrm{p} / \mathrm{v}$ haemorrhage and stomach pain. After that, there is a per-vaginum discharge. At the end of the 12-month follow-up, the continuation rate was 94.61 percent.

Conclusion: The benefits of contraceptive protection outweigh the potential inconvenience of needing to return for care for women who receive PPIUCD, and the rates of expulsion were low enough.

Keywords: Intrauterine contraceptive device, Postpartum, Acceptance, Counselling, Complications.
\end{abstract}

\section{Introduction}

Long-acting contraceptives are promoted and made available to all eligible women seeking long-term spacing. ${ }^{[1]}$ According to a survey conducted by the National Family Health Service
(NFHSH-4), India's total unmet contraceptive need is 12.9 percent, and its unmet spacing need is 5.7 percent. ${ }^{[2]}$ Hence good contraceptive coverage in the reproductive age group population not only bring the population under control but also pave a 
path to better health care in India by bringing down the burden on health care infrastructure.

The intrauterine contraceptive device (IUCD) is a highly effective (99\%) and low-cost family planning tool that is reversible, needs no effort on the user's part once installed, and provides 5-10 years of pregnancy protection. ${ }^{[3]}$ IUCD is used by roughly one out of every five women of reproductive age around the world, but only about three out of every hundred women in India utilise it. ${ }^{[4]}$

Although the government of India provides the Copper T 380A (CuT380A) device free of charge and it is effective for ten years, it is still generally unused. There are several myths and misconceptions, and the benefits are downplayed, while the risks and side effects are overstated. ${ }^{[5]}$ The effectiveness of various copper IUD devices has been studied by a number of researchers. The published cumulative pregnancy rate for the Copper T-380A's remaining contraceptive life lifetime has always been exceptionally low, at 2.2 per100 women. ${ }^{[6]}$

IUCD has some unpleasant side effects, but they are not hazardous, and they usually go away within a few months in most women. The provider's knowledge and up-to-date information, correct case selection, and pre- and post-insertion counselling of patients and family members about probable adverse effects and the benign nature of the procedure can all help to reduce the discontinuation rate and boost acceptability. ${ }^{[7]}$

\section{Aim}

In a single setting in the Indian scenario, studies comparing IUCD insertion immediately after vaginal and caesarean delivery, in the delayed postpartum period, and after 6 weeks are scarce. As a result, we conducted our research in an Indian tertiary care centre that serves a vast population. At a tertiary-care centre in south India, we aimed to compare numerous IUCD-related clinical parameters to assess acceptability, safety, and efficacy in immediate postpartum vaginal insertion, intra-caesarean insertion.

\section{Materials and Methods}

This is a prospective observational study conducted at a tertiary care teaching medical college and hospital in Tamil Nadu. The women presenting to antenatal OPD were counselled about family planning and encouraged to opt for cu- $\mathrm{T}$ insertion immediately after delivery. The women presenting to labour room were counselled and invited to participate in the study. All postpartum patients who are willing to use IUCD for contraception in post-partum period were included in this study from January 2017 to October 2020.

In this study copper T 380A was used. Insertion was done by trained obstetricians who followed all recommended clinical and infection prevention measures for successful insertion as per the national family welfare guidelines. Before hospital discharge all the patients were examined for vaginal bleeding and discharge. At 6 weeks, 6 months and one year interval follow up visit were scheduled. During the follow up visit, all patients were undergone pelvic examination to check for any signs of bleeding, infection, displacement and abdominal USG to check the IUCD position. Expulsions were confirmed clinically and radiologically.

The study was analysed the data using SSPS 11.6 software, all the categorical data is presented with frequency and percentage.

\section{Inclusion Criteria}

- Women fulfilling WHO medical eligibility criteria.

- Women who gave informed written consent and had either vaginal delivery or caesarean section.

Patients were subdivided into three categories based on timing of insertion and mode of delivery. Post placental insertion was done within 10 minutes of delivery in labour ward. Immediate postpartum insertion was done within 48 hours of delivery in post-natal ward. Intra caesarean insertion that takes place during a caesarean delivery, after removal of the placenta and before closure of the uterine incision 


\section{Exclusion Criteria}

Patients who had the following conditions were excluded from the study,

- Pregnant patients who were below 28 weeks gestation

- Genital tuberculosis

- PPH (postpartum haemorrhage)

- Uterine fibroids \& anomalies

- PROM $>12$ hours

- History of ectopic pregnancy in the past.

\section{Sample Size}

In this study 850 patients were counselled for postpartum IUCD insertion, out of which 354 patients accepted and were followed up for oneyear post IUCD insertion.

\section{Results}

In this study 675 patients were counselled for postpartum IUCD insertion, out of which 354 [52.88\%] of patient accepted the procedure [Table1]. Out of 354 cases who accepted for PPIUCD, majority of patient belong to 26-30 years of age group [51.97\%]. Majority of women opting for PPIUCD are of middle and low socioeconomic class [64.4\%]. This may be due to the fact that these women are taking services more at authors setup. In present study, out of 354 patient greater number of primipara patients are accepting PPIUCD [55.93\%] and who were employed [66.94\%]. [Table 2]
More number of patients opting PPIUCD during post LSCS and post placental PPIUCD suggest a greater number of counselling during antenatal period and during early labour. Post placental is more common in our study $(50.0 \%)$ compare to intra caesarean insertion (27.96\%) and postpartum PPIUCD consist of (22.08\%). [Table 3].

Follow up rate was about $70.05 \% \%$ in 6week (i.e.248 patients out of 354 patient). After 6 months, it was increased to $80.79 \%$ and was reduced up to $74.57 \%$ at 12 months. [Table 4]

In present study, follow up at 6 weeks, months and 1 year, leukorrhea and abdominal pain was the common side effect followed by bleeding $\mathrm{p} / \mathrm{v}$ (Table 5). No perforation found in present study. None of the studies as per literature search have reported uterine perforation after PPIUCD insertion. Missing string was no problem up to six month follow up, but it was found in cases at one year of follow up.

The continuation rate i.e. number of women continuing the IUCD inserted in the postpartum was $94.61 \%$ at the end of $12^{\text {th }}$ month of follow up. [Table -6]

In the study it was found that 20 patients removed $\mathrm{cu}-\mathrm{T}$, maximum number of $\mathrm{Cu}-\mathrm{T}$ removed due to bleeding $\mathrm{p} / \mathrm{v}$ and abdominal pain. (each no 4) followed by discharge pervaginum (i.e. 2). [Table7]

Table 1 Characteristics of subjects counselled for IUCD use

\begin{tabular}{|lccc|}
\hline Characteristic & Antenatal counselling [n \%] & Postpartum counselling [ $\mathrm{n} \%$ ] & TOTAL \\
\hline Acceptors & $276[40.98 \%]$ & $78[11.70 \%]$ & $354[52.88 \%]$ \\
Refusers & $217[32.14 \%]$ & $104[15.40 \%]$ & $321[47.55 \%]$ \\
Total counselled & 493 & 182 & 675 \\
\hline
\end{tabular}

Table 2 Demographic and clinical profile of studied women

\begin{tabular}{|c|c|c|c|}
\hline S. No & Variables & PPIUCD acceptors & Acceptance rate \\
\hline \multicolumn{4}{|c|}{$1 \quad$ Maternal age } \\
\hline & $<20$ & 22 & $6.21 \%$ \\
\hline & $21-25$ & 118 & $33.33 \%$ \\
\hline & $26-30$ & 184 & $51.97 \%$ \\
\hline & $>31$ & 32 & $9.03 \%$ \\
\hline \multirow[t]{5}{*}{2} & Maternal education status & & \\
\hline & No formal education & 36 & $10.16 \%$ \\
\hline & Primary & 116 & $32.76 \%$ \\
\hline & Secondary & 167 & $47.17 \%$ \\
\hline & Higher education & 35 & $9.88 \%$ \\
\hline
\end{tabular}


3 Maternal socioeconomic status

126

$35.59 \%$

Middle/lower

228

$64.40 \%$

4 Mother occupation

$\begin{array}{lcc}\text { Employed } & 237 & 66.94 \% \\ \text { Unemployed } & 117 & 33.05 \%\end{array}$

5 Parity

\begin{tabular}{lll} 
Primipara & 198 & $55.93 \%$ \\
Multipara & 156 & $44.06 \%$ \\
\hline
\end{tabular}

Table 3 Time of insertion of IUCD among patients

\begin{tabular}{|l|c|}
\hline \multicolumn{1}{|c|}{ TIME OF INSERTION } & NO OF CASE [\%] \\
\hline Caesarean & $99[27.96 \%]$ \\
\hline Post placental & $177[50.00 \%]$ \\
\hline Within 48 hours of delivery & $78[22.03 \%]$ \\
\hline
\end{tabular}

Table 4 Distribution based on follow-up of patients after IUCD insertion

\begin{tabular}{|l|c|c|}
\hline TIME INTERVEL & \multicolumn{2}{|c|}{ NUMBER [\%] } \\
\hline After 6 Weeks & YES & $248[70.05 \%]$ \\
\cline { 2 - 3 } & NO & $106[29.94 \%]$ \\
\hline \multirow{2}{*}{ After 6 Months } & YES & $286[80.79 \%]$ \\
\cline { 2 - 3 } & NO & $68[19.20 \%]$ \\
\hline \multirow{2}{*}{ After 1 Year } & YES & $264[74.57 \%]$ \\
\cline { 2 - 3 } & NO & $90[25.64 \%]$ \\
\hline
\end{tabular}

Table 5 Complications of PPIUCD at the time of follow-up visit in one year

\begin{tabular}{|l|c|}
\hline COMPLICATIONS & No of case \\
\hline Abdominal pain & $14[3.9 \%]$ \\
\hline Leukorrhea & $24[6.77 \%]$ \\
\hline Bleeding per vaginum & $11[3.10 \%]$ \\
\hline Missing thread & $3[0.84 \%]$ \\
\hline Bleeding and abdominal pain & $16[4.51 \%]$ \\
\hline Expulsion & $6[1.69 \%]$ \\
\hline Perforation & $0[0 \%]$ \\
\hline
\end{tabular}

Table 6 Association between time of insertion and continuation of IUCD

\begin{tabular}{|l|c|c|}
\hline \multirow{2}{*}{ TIME OF INSERTION } & \multicolumn{2}{|c|}{ Continued use of IUCD after 12 months } \\
\cline { 2 - 3 } & YES & NO \\
\hline Caesarean & $92[25.98 \%]$ & $7[1.9 \%]$ \\
\hline Post placental & $172[48.58 \%]$ & $6[1.6 \%]$ \\
\hline $\begin{array}{l}\text { Within 48 hours of } \\
\text { delivery }\end{array}$ & $71[20.05 \%]$ & $7[1.9 \%]$ \\
\hline
\end{tabular}

Table 7 Causes of removal of IUCD over a period of 12 months

\begin{tabular}{|l|c|}
\hline Cause of Removal & No of case $=20$ \\
\hline Bleeding P/V & $4[20 \%]$ \\
\hline Discharge P/V & $2[10 \%]$ \\
\hline PID/Pain & $4[20 \%]$ \\
\hline For Conception & $0[0 \%]$ \\
\hline Othersocial factor & $10[50 \%]$ \\
\hline
\end{tabular}

\section{Discussion}

The IUCD is a reversible and long-lasting technique of birth control. The postpartum time allows a healthcare provider to counsel a lady about family planning services in order to avoid unplanned pregnancy. Women who have been counselled for PPIUCD had a 10 times higher risk of employing IUCD than those whose insertion 
was postponed until the uterus had completely involved. $^{[8]}$

Following vaginal and caesarean delivery, the immediate post placental implantation is an optimal moment to achieve long-term contraception with minimal discomfort to the woman, and it is becoming more popular due to its safety and decreased expulsion rates. ${ }^{[9,10]}$

A total of 675 patients were counselled for postpartum IUCD insertion in this study, with 52 percent of them agreeing to the procedure. The majority of them refused owing to a lack of knowledge about contraception and a fear of complications. Acceptance was based on the fact that it was a reversible contraception method. In the current study, women of reproductive age 2630 years opted for PPIUCD at a rate of 51.97 percent, with middle and low socioeconomic class women selecting for PPIUCD at a rate of 64.4 percent. This could be attributable to a higher proportion of lower socioeconomic class patients visiting our hospital.

The majority of the women in the sample group (57.05 percent) had completed at least secondary school. Women with higher and secondary education were more accepting of PPIUCD (9.88 percent and47.17 percent). This was comparable to a research by Safwat et al ${ }^{[11]}$ and Thomas $\mathrm{D}^{[12]}$ in Egypt.

Patients were primipara 55.93 percent of the time and multipara 44.06 percent of the time. Primiparas had a higher level of acceptance, which aided in optimum birth spacing. Similar findings were obtained in a study by Maluchuru $S$ et al, Gautam R et al, and Vidyarama R et al, who showed that primipara acceptability was greater at 15.42 percent, 71.91 percent, and 15.47 percent, respectively. This is similar to what Grimes et al discovered in their investigation. ${ }^{[2]}$

The acceptability rates for vaginally delivered patients and LSCS patients were 72.03 percent and 27.96 percent, respectively, in this study. Patients delivering vaginally showed higher approval with post placental insertion (45.9\%), compared to just $(3.5 \%)$ in the group getting insertion within the first 48 hours, indicating that acceptability is higher when insertion is done within 10 minutes after placenta delivery. This is similar to Goswami et al's study, which found that acceptance. ${ }^{[13]}$

In this study, 354 patients were observed for six weeks, six months, and one year. At 6 months, 68 patients had not been followed up on. The majority of follow-up is due to improved methods and more post-LSCS insertion, as a result of concerns about post-operative problems. Only 12 women suffered issues such as leucorrhoea, bleeding, pain abdomen, and expulsion when the authors assessed the safety of the PPIUCD. This is comparable to the study by Mishra S. Gupta. In a study conducted by $\mathrm{A}$ et al in a western Uttar Pradesh hospital, $8 \%$ of patients reported per vaginal haemorrhage. ${ }^{[14]}$

Expulsion of IUCD is a significant aspect that affects the device's efficacy. In the current analysis, 6 (1.6 percent) patients experienced IUCD expulsion with a maximum of 6 to 12 months, whereas Celen $S$ et al. ${ }^{[10]}$ had a 17.6 percent expulsion rate at the end of 12 months.

In the current study, 20 patients had their IUCD removed for a variety of causes, including bleeding (20\%), abdominal pain (20\%), others $(10 \%)$, and the remaining $(50 \%)$ had their IUCD removed owing to misperceptions such as discomfort and fear of displacement into the abdomen. Mishra $\mathrm{S}^{[15]}$ and Sharma A et al ${ }^{[16]}$ found that the cumulative elimination rate was $7 \%$ and 13.5 percent, respectively, in their studies. Psychosocial issues were the most common reason for removal, followed by menstruation issues and persistent pelvic pain.

\section{Conclusion}

The current study found that PPIUCD has a high level of acceptance, which is comparable to other global studies. Despite high acceptance, many women had little knowledge of the PPIUCD. The PPIUCD was unfamiliar to the majority of the women, and acceptance was higher among educated women and primigravida. The benefits 
of contraceptive protection outweigh the potential inconvenience of needing to return for care for women who receive PPIUCD.

\section{Reference}

1. WHO Unmet Need for Family Planning. Available from: http;//www.who.int/reproductivehealth/top ics/family planning/unmet need fp/en.

2. LA Lopez. LM Grimes. D. A et all immediate post-partum insertion of intrauterine devices. Cochrane database System. Rev 2010:5: CD 003036'.

3. Azmat SK, Shaikh BT, Hameed W, Bigrami M, Mustafa G, Ali M, et al. Rates of IUCD discontinuation and its associated factors among the clients of a social franchising network in Pakistan. BMC Women's Health 2012; 12:8.

4. IUD Guidelines for Family Planning Service Programs. Available from: http://www.jhpiego.org/files/IUD_ Manual_0.pdf.

5. Grimes DA, Lopez LM, Schulz KF, Van Vliet HA, Stanwood NL. Immediate postpartum insertion of intrauterine devices. Cochrane Database Syst Rev. 2010;5:CD003036.

6. Long-term reversible contraception. Twelve years of experience with the TCu380A and TCu220C. Contraception. 1997; 56:341-352

7. Megha Sharma, Shubham Joshi, Obey Nagar, and Akash Sharma J Obstetric Gynaecology India. 2014 Jun; 64(3): 208211.

8. Thonneau P F, Almont T. Contraceptive efficacy of intrauterine devices. Am $\mathrm{J}$ Obstetric Gynecol. 2008; 198(3): 248-53.

9 Xu J X, Reusché C, Burdan A. Immediate post placental insertion of the intrauterine device: a review of Chinese and the world's experiences. Adv Contracept. 1994; 10(1): 71-82.
10 Celen S, Moroy P, Sucak A, Aktulay A, Danisman N. Clinical outcomes of early post placental insertion of intrauterine contraceptive devices. Contraception. 2004; 69: 279-82.

11 Safwat A, Mohamed Momen A, Kamel Omar M, et al. Acceptability for the use of postpartum intrauterine contraceptive devices: assiut experience. Med Prince Proact. 2003; 12: 170-175

12 Thomas D, Maluccio J. Fertility, contraceptive choice, and public policy in Zimbabwe. World Bank Econ Rev. 1996; 10(1): 189-222.

13 Goswami G, Yadav K, Patel A. A prospective study to evaluate safety, efficacy and expulsion rate of post placental insertion of intra uterine device. J Evol Med Dent Sci. 2015;4(56):9770.

14 Gupta A, Verma A, Chauhan J. Evaluation of PPIUCD versus interval IUCD (380A) insertion in teaching hospital of western Uttar Pradesh. Int J Reprod Contracept Obstetric Gynecol. 2013;2(2):294-8

15 Mishra S. Evaluation of safety, efficacy and expulsion of post placental and Intra caesarean insertion of intrauterine contraceptive devices. J Obstetric Gynecol India. 2014; 64(5): 337-43.

16 Arti Sharma, Vineeta Gupta, Neeta Bansal, Utkarsh Sharma ,Archna Tandon.A study of immediate postpartum intra uterine device insertion in a tertiary level hospital International Journal of Research in Medical Sciences Sharma A et al. Int J Res Med Sci.2015 Jan; 3(1): 183-187. 